\title{
Shared Tobacco Cessation Curriculum Website for Health Professionals: Longitudinal Analysis of User and Utilization Data Over a Period of 15 Years
}

Nervana Elkhadragy ${ }^{1}, \mathrm{PhD}$, PharmD; Jeremie Aviado ${ }^{2}$, PharmD; Henry Huang ${ }^{2}$, PharmD; Robin L Corelli ${ }^{2}$, PharmD; Karen Suchanek Hudmon ${ }^{2,3}$, DrPH

\footnotetext{
${ }^{1}$ School of Pharmacy, University of Wyoming, Laramie, WY, United States

${ }^{2}$ Department of Clinical Pharmacy, School of Pharmacy, University of California San Francisco, San Francisco, CA, United States

${ }^{3}$ Department of Pharmacy Practice, College of Pharmacy, Purdue University, West Lafayette, IN, United States
}

\section{Corresponding Author:}

Karen Suchanek Hudmon, DrPH

Department of Pharmacy Practice

College of Pharmacy

Purdue University

575 Stadium Mall Drive

West Lafayette, IN

United States

Phone: 13178805427

Email: khudmon@purdue.edu

\section{Abstract}

Background: Because tobacco use is a major cause of morbidity and mortality worldwide, it is essential to prepare health care providers to assist patients with quitting smoking. Created in 1999, the "Rx for Change" tobacco cessation curriculum was designed to fill an educational gap in cessation training of health professional students. In 2004, a website was launched to host teaching materials and tools to support the efforts of educators and clinicians.

Objective: The objective of this study was to characterize users and utilization of a website hosting shared teaching materials over a period of 15 years.

Methods: Data from the Rx for Change website have been collected prospectively since its inception. In this study, end-user data were analyzed to determine user characteristics, how they heard about the website, intended use of the materials, and numbers of logins and file downloads over time.

Results: Total number of website registrants was 15,576, representing all 50 states in the United States and 94 countries. The most represented discipline was pharmacy $(6393 / 15,505,41.2 \%)$, and nearly half of users were students or residents. The most common source of referral to the website was a faculty member or colleague $(33.4 \%, 2591 / 7758)$, and the purpose of enhancing personal knowledge and skills was the most commonly cited intended use of the curricular materials. A total of 259,835 file downloads occurred during the 15-year period, and the most commonly downloaded file type was ancillary handouts.

Conclusions: The Rx for Change website demonstrated sustained use, providing immediate access to tobacco cessation teaching and practice tools for educators and clinicians over the first 15 years of its existence. The website has a broad interprofessional reach, and the consistent utilization over time and large number of downloads provide evidence for the feasibility and utility of a public-access website hosting teaching materials. The shared curriculum approach averts the need for educators to create their own materials for teaching tobacco cessation to students in the health professions.

(JMIR Med Educ 2021;7(2):e20704) doi: 10.2196/20704

\section{KEYWORDS}

health professional education; interprofessional education; shared curricula; website; end-user data; tobacco cessation 


\section{Introduction}

Tobacco use is a major cause of morbidity and mortality worldwide, with more than 8 million deaths each year due to tobacco use or exposure to second-hand smoke [1]. In the United States, more than 480,000 deaths a year are attributable to cigarette smoking; of these, $33 \%$ are due to cardiovascular diseases, $27 \%$ lung cancer, $23 \%$ pulmonary diseases, $9 \%$ second-hand smoke, and 7\% cancers other than lung [2]. Through multifaceted tobacco control efforts, significant progress has been made over the past several decades to reduce the overall prevalence of cigarette smoking among adults from $40 \%$ in 1964 to $14.0 \%$ in 2019 [3]. In recent years, however, the emergence of alternative nicotine delivery systems (ANDS; eg, e-cigarettes and other vaping methods) [4] has been reversing the downward trend of tobacco use, with $4.5 \%$ of adults reporting current use of e-cigarettes [3] and 20.8\% currently using one or more forms of tobacco or ANDS. As such, tobacco use remains a public epidemic, predisposing individuals to an increased risk for developing diseases of virtually every organ system in the body and contributing to rising health care costs [2]. For each pack of cigarettes sold in the United States, the societal costs due to smoking-related health care costs and lost productivity are estimated at US $\$ 19.16$ per pack, which is around 3 times the cost of the cigarettes [5].

It is well established that clinicians have a proven positive impact on their patients' ability to quit [6]. To achieve reductions in the public health burden of tobacco, the 2020 Surgeon General's report on smoking cessation highlights the importance of clinical interventions by health care providers of all disciplines [7]. Three factors should be considered when attempting to improve quit rates: (1) the efficacy of interventions on patients' ability to quit, (2) fidelity to implementing tobacco cessation interventions in clinical settings, and (3) clinicians' knowledge and skills for treating tobacco use and dependence. In regards to efficacy, research shows that clinician interventions that are based on the $5 \mathrm{~A}$ 's (Ask, Advise, Assess, Assist, and Arrange) are effective and increase quit rates among patients and thus is considered a gold standard for comprehensive counseling [6]. Fidelity considers the extent to which the $5 \mathrm{~A}$ 's are integrated into practice, in the face of challenges such as lack of time, competing demands, and lack of providers' self-efficacy for tobacco cessation counseling [8]. To mitigate these challenges, investigators have explored creative approaches to enhance the delivery of care (eg, Satterfield and colleagues [9] found that a computer-facilitated 5 A's approach performs better than usual care). The third aspect that can influence quit rates is clinicians' knowledge and skills for providing tobacco cessation interventions. To address this, the "Rx for Change Clinician-Assisted Tobacco Cessation" curriculum was designed, and its corresponding website [10] was launched to host the tobacco cessation teaching and counseling materials. The Rx for Change curriculum, and the website described here, aim to enhance the quality and quantity of tobacco counseling that occurs in clinical practice.
Historically, the extent of tobacco cessation content has been inadequate in all health professional school curricula, including medical [11-15], nursing [16-19], pharmacy [20,21], dental hygiene [22], physical therapy [23], physician assistant [24], and respiratory therapy [25,26]. The evidence-based $\mathrm{Rx}$ for Change curriculum was a practical solution to address this decades-long gap [27]. The term "Rx" means prescription, and a "curriculum" is defined as "the totality of student experiences that occur in the educational process" [28]. As such, Rx for Change is a curriculum about tobacco cessation that was designed to teach health professional students and licensed clinicians. Rogers' Diffusion of Innovations Theory [29] served as a guiding framework for program design, aiming to enhance the adoptability of the curricular innovation and structure future dissemination strategies. A key strategy for dissemination of $\mathrm{Rx}$ for Change occurred via targeted in-person and virtual train-the-trainer workshops for faculty at health professional schools (pharmacy, nursing, medicine, and respiratory care).

To facilitate integration of the $\mathrm{Rx}$ for Change curriculum at health professional schools, a public-access website was created to host all of the Rx for Change curricular materials (Figure 1). Several versions of the curriculum exist, each addressing a different clinical specialty for which patients can benefit from tobacco cessation interventions. Learning objectives are provided for each of the program's modules. PowerPoint slides, with detailed instructor notes, and learner handouts are downloadable and can be used by educators to teach in a lecture-based format. Additional teaching materials include dozens of videos (Figure 2), case materials for role playing, ancillary handouts for clinicians and patients, and a suite of tobacco-specific virtual patients. To facilitate assessment of counseling competencies, 6 standardized patient cases were created with associated scoring rubrics for conducting objective structured clinical examinations (OSCEs). Tools are also available to assist faculty with implementation of all aspects of the curriculum. The U.S. Surgeon General provides a 3-minute introductory video, highlighting the importance of integrating tobacco cessation into clinical practice (Figure 1).

Educational experts have placed much value on developing effective training programs and have also emphasized the need for program evaluation [30]. Unfortunately, when websites are created to host educational materials, these resources are often short-lived before becoming outdated and dormant after institutional support or grant funds expire. Launched in 2004, the Rx for Change website teaching content is updated at least annually and also when needed to address changes in clinical practice (eg, postlaunch of a new medication, inclusion or removal of a boxed warning). However, its usage has yet to be characterized. Such knowledge would be helpful to understand the impact of providing shared curricular materials through a public access website and to inform future curriculum developers about potential usage and benefits of hosting shared materials online. Therefore, the purpose of this study was to conduct a longitudinal analysis of user characteristics and utilization of the Rx for Change website over a period of 15 years. 
Figure 1. Rx for Change website homepage [10].

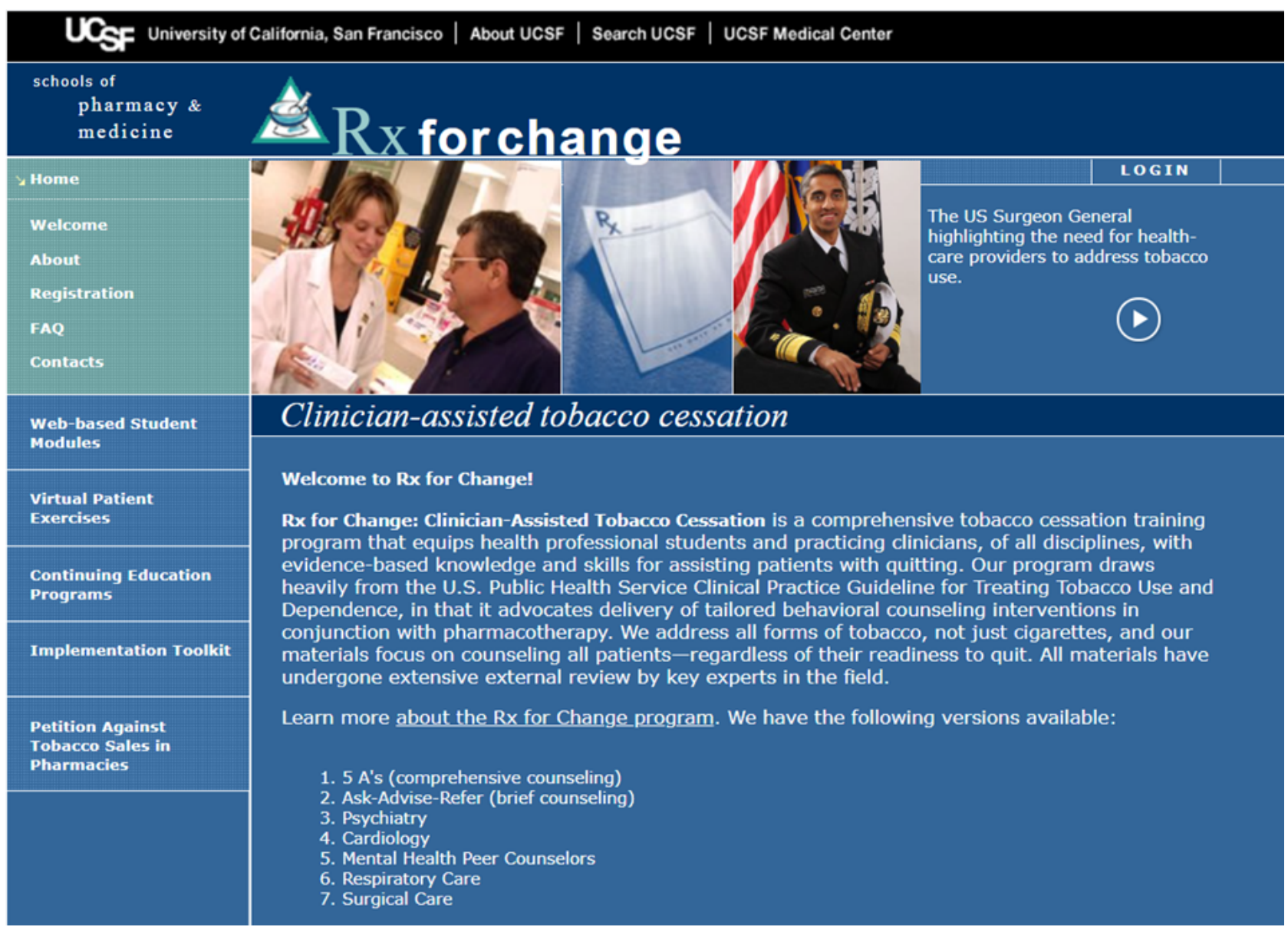

Figure 2. Rx for Change website: sample page hosting tobacco "trigger tape" videos.

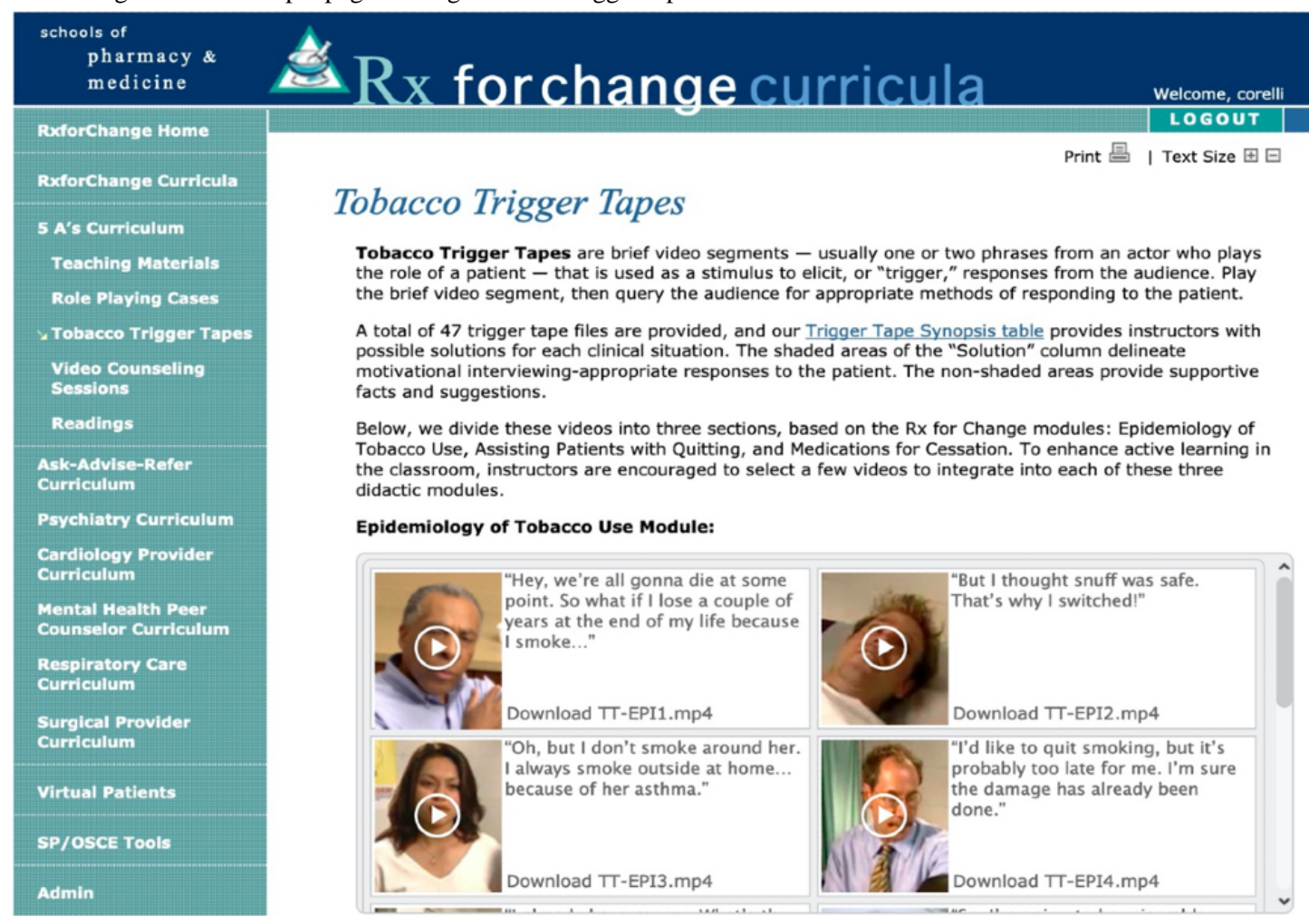




\section{Methods}

User and utilization data have been collected prospectively via the Rx for Change website since its launch in 2004. For the purpose of this study, data were extracted for a period of 15 years, ranging from the public launch date on April 1, 2004 to March 31, 2019. Individuals who registered on the website provided contact information, including their state and country, their primary discipline (medicine, nursing, pharmacy, respiratory care, dentistry, health educator/peer counselor, social work, other), and whether they were a student or resident. Additional information included how they heard about the Rx for Change program (conference/meeting/workshop; faculty member/colleague; internet LISTSERV; newsletter or publication; surfing the internet; University of California San Francisco Smoking Cessation Leadership Center; other) and their intended use of the materials (enhance own knowledge/skills; teach health professional students; teach licensed health professionals; not sure). In addition to user characteristics, prospectively collected data included various utilization measures: files downloaded (frequency and type), number of file downloads per user, number of logins, and trends in utilization over time. All video files on the website are permitted to be streamed directly on the website, and these occurrences were not linkable to individual users and therefore were not captured along with the number of file downloads.

With respect to data interpretation, it is important to note that not all programmatic materials were available at the launch of the website in 2004 - a version addressing brief counseling (Ask-Advise-Refer) was launched in November 2007, and new discipline-specific versions (eg, psychiatry, respiratory care, peer counselor, cardiology, and surgical care) became available over time. Along with the annual updates, new videos and role-playing case materials were added periodically, and all were modified as needed to be consistent with evolving clinical practice guidelines. In 2019, a suite of 6 standardized patient cases with scoring rubrics for OSCEs were added along with a link to a suite of tobacco-specific virtual patients [31]. No proactive efforts were made (eg, no email notifications) to alert users of the availability of new or updated content, and at no time during the 15-year period was the website inaccessible for more than a few hours at a time during updates or server maintenance.

Data cleaning occurred at the individual user level, which included combining duplicate registrants (eg, identical users who established separate accounts with different email addresses), reclassifying disciplines where appropriate, and recategorizing data response options labeled as "other" (eg, user checked "other" for the discipline field but provided information consistent with existing response options). Combining duplicate registrants was done by manually reviewing registrations that appeared to belong to the same person, and after extensive investigation through internet search engines and LinkedIn profiles, discussion, and consensus, the team determined when it was appropriate to attribute multiple registrants to the same user. Data were analyzed using SPSS, version 26 [32]. The study was approved by the University of California, San Francisco and Purdue University Institutional Review Boards for the protection of human subjects.

\section{Results}

\section{User Characteristics}

A total of 15,576 unique users registered on the Rx for Change website during the study period. Registrants represented all 50 states in the United States and 94 different countries. Among users with a designated health discipline (15,505/15,576, $99.5 \%)$, the top represented disciplines were pharmacy $(6393 / 15,505,41.2 \%)$, followed by nursing $(3377 / 15,505$, $21.8 \%)$ and health educators/peer counselors (1653/15,505, 10.7\%; Table 1). Students and residents represented $49.7 \%$ $(7747 / 15,576)$ of all registrants.

Table 1. Represented disciplines among $15,505^{\mathrm{a}}$ end users reporting discipline and student or resident status.

\begin{tabular}{llll}
\hline Disciplines & Nonstudent or nonresident $(\mathrm{n}=7758), \mathrm{n}(\%)$ & Student or resident $(\mathrm{n}=7747), \mathrm{n}(\%)$ & Total $(\mathrm{n}=15,505), \mathrm{n}(\%)$ \\
\hline Pharmacy & $1790(23.1)$ & $4603(59.4)$ & $6393(41.2)$ \\
Nursing & $1305(16.8)$ & $2072(26.7)$ & $3377(21.8)$ \\
Health educator or peer counselor & $1461(18.8)$ & $192(2.5)$ & $1653(10.7)$ \\
Medicine & $677(8.7)$ & $239(3.1)$ & $916(5.9)$ \\
Respiratory care & $440(5.7)$ & $127(1.6)$ & $567(3.7)$ \\
Dentistry & $174(2.2)$ & $87(1.1)$ & $261(1.7)$ \\
Social work & $112(1.4)$ & $21(0.3)$ & $133(0.9)$ \\
Other & $1799(23.2)$ & $406(5.3)$ & $2205(14.2)$ \\
\hline
\end{tabular}

$\mathrm{a}_{71}(0.5 \%)$ end users did not provide data describing their student/resident status and discipline.

${ }^{\mathrm{b}}$ Includes physicians and physician assistants.

Of nonstudents/nonresidents, approximately one third $(2591 / 7758,33.4 \%)$ reported hearing about the website from a faculty member or colleague; the remainder heard about the website at a conference, meeting, or workshop (1305/7758,
$16.8 \%)$; while surfing the internet $(1295 / 7758,16.7 \%)$; on an internet LISTSERV (734/7758, 9.5\%), distributed by the University of California Smoking Cessation Leadership Center $(531 / 7758,6.8 \%)$, or in a newsletter publication or article 
$(468 / 7758,6.0 \%)$. The most commonly selected intended use of the Rx for Change materials was to enhance personal knowledge and skills (5792/7308, 79.3\%); 39.2\% (2867/7308) intended to teach licensed health professionals, and $33.2 \%$ (2425/7308) indicated that they intended to teach health professional students (categories not mutually exclusive).

\section{Website Utilization Characteristics}

During the evaluation period, 259,835 files were downloaded by 12,387 users, representing $79.5 \%(12,387 / 15,576)$ of all website registrants. While the remainder of the registrants $(3189 / 15,576 ; 20.5 \%)$ might have streamed videos on the website, they did not download any files. The file type most commonly downloaded was ancillary handouts $(n=61,348)$, followed by counseling videos $(n=58,109)$ and instructors' PowerPoint slides ( $n=49,501$; Table 2). Across the 15-year time period, users logged into the website a total of 62,172 times. Login frequency and download frequency trends over time are shown in Figure 3.

Table 2. File downloads $(n=259,835)$ by teaching tool.

\begin{tabular}{|c|c|c|}
\hline Teaching tool & Description of tool & Number of downloads, $\mathrm{n}(\%)$ \\
\hline Ancillary handouts & $\begin{array}{l}\text { Tools that clinicians can use when helping patients (eg, tobacco cessation counseling } \\
\text { guide, withdrawal symptoms information sheet, drug interactions with tobacco smoke } \\
\text { table, tobacco use log, coping strategies for patients, pharmacologic product guide) }\end{array}$ & $61,348(23.6)$ \\
\hline Counseling videos & $\begin{array}{l}\text { Video segments demonstrating counseling of a wide range of patients (not ready to quit, } \\
\text { ready to quit, recent quitter, former tobacco user) in many patient care settings }\end{array}$ & $58,109(22.4)$ \\
\hline Learner slide handouts & PDF versions of the PowerPoint slides & $32,024(12.3)$ \\
\hline Role playing cases & $\begin{array}{l}\text { Handouts for role playing with a wide range of patient case scenarios (not ready to quit, } \\
\text { ready to quit, recent quitter, former tobacco user) }\end{array}$ & $22,809(8.8)$ \\
\hline Trigger tape videos & $\begin{array}{l}\text { Brief video segments ( } 1-2 \text { phrases from an actor who plays the role of a patient) that are } \\
\text { used as a stimulus to elicit, or "trigger," discussion with learners }\end{array}$ & $17,959(6.9)$ \\
\hline Instructor tools & Guides and other resources to facilitate implementation of the $\mathrm{Rx}$ for Change curriculum & $8749(3.4)$ \\
\hline Introductory videos & $\begin{array}{l}\text { A } 3 \text {-minute video created by the U.S. Surgeon General highlighting the need for health } \\
\text { care providers to address tobacco use and an 8-minute introductory video of interviews } \\
\text { with smokers }\end{array}$ & $3582(1.4)$ \\
\hline Reading materials & $\begin{array}{l}\text { Recommended background readings (eg, PDF versions of textbook chapters and contin- } \\
\text { uing education programs on tobacco cessation) }\end{array}$ & $3451(1.3)$ \\
\hline Administrative tools & End-user license agreement, sample medication order forms, tracking forms, etc. & $2213(0.9)$ \\
\hline OSCE $^{\mathrm{a}}$ case materials & $\begin{array}{l}\text { Standardized patient cases, with corresponding scoring rubrics for formative and evaluative } \\
\text { exercises }\end{array}$ & $90(<0.01)$ \\
\hline
\end{tabular}

${ }^{a}$ OSCE: objective structured clinical examination; these competency assessment tools became available on the website in 2018. 
Figure 3. Number of files downloaded and number of logins, per year (April 1, 2004 to March 31, 2019).

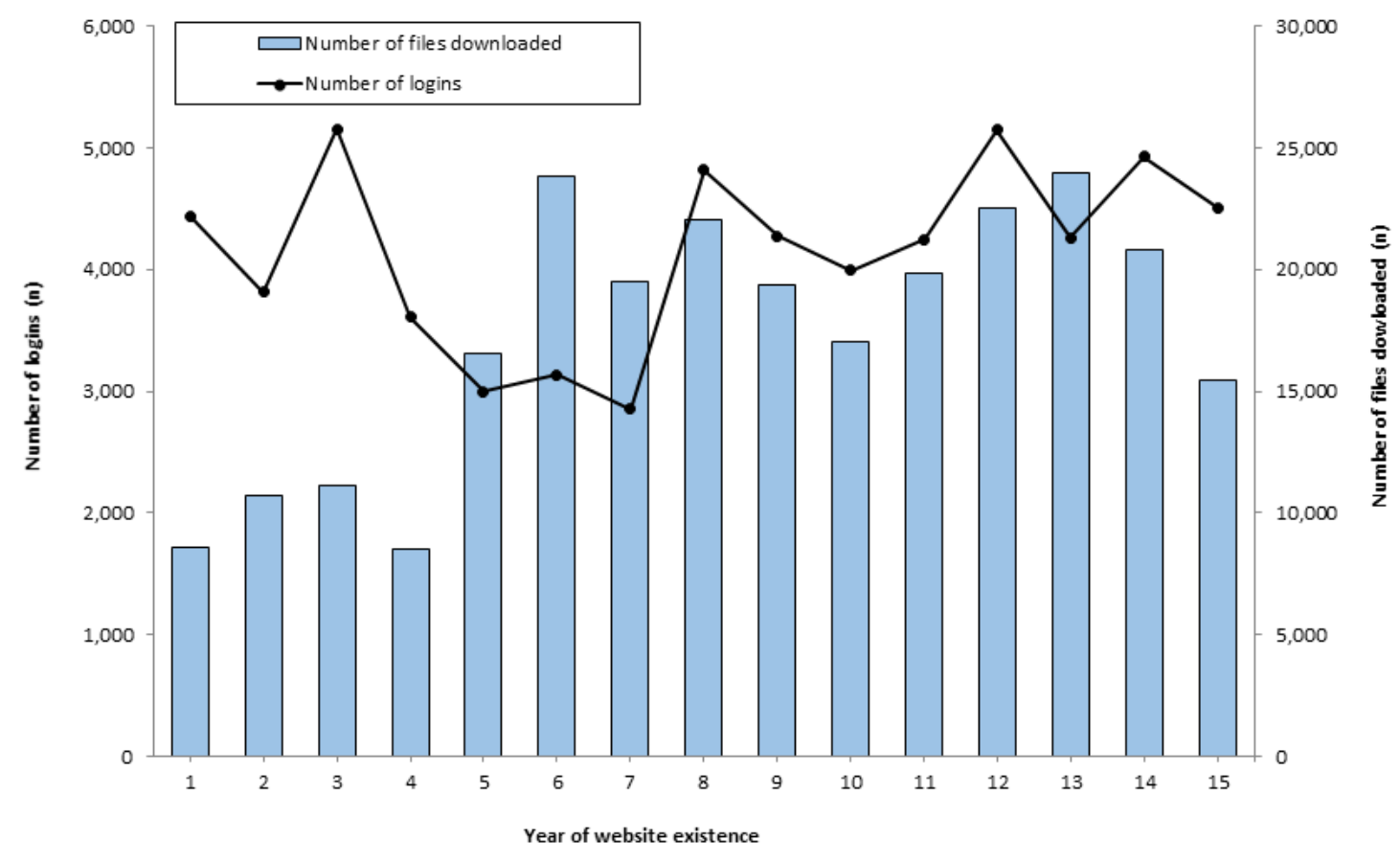

\section{Discussion}

\section{Principal Findings}

This study contributes important knowledge to the literature regarding the extent to which health professional educators, clinicians, and students utilize a website that was designed to house and disseminate educational materials for tobacco cessation. The study complements our concurrent research evaluating the Rx for Change program, thus providing a more complete picture of the program's reach and long-term impact [33]. Although an abundance of existing literature describes web-based interventions for tobacco cessation [34], to our knowledge, there are no studies that characterize internet-based access to tools designed to facilitate faculty and students in their teaching and learning roles and clinicians in their patient care roles. Current literature addressing professional educational websites other than tobacco cessation is also scarce. We identified 3 websites that house teaching materials (pharmacogenomics, infectious diseases, and diabetes mellitus) [35-37], but utilization of these sites have not been described in the literature. In addition to widespread use of the website over a period of 15 years, the Rx for Change materials have been used in a variety of tobacco cessation studies across several health disciplines [38-51]. Recently, the long-term impact of the train-the-trainer programs on faculty development and Rx for Change implementation in pharmacy schools was evaluated through application of the RE-AIM framework [52,53].

Rogers' Diffusion of Innovation Theory [29], which was used to develop and disseminate the Rx for Change curriculum, was also used to guide elements of data interpretation. This theory states that new programs are more likely to exhibit enhanced adoption if they possess 5 main characteristics: (1) relative advantage over existing programs; (2) compatibility with existing values, experiences, and needs of potential adopters; (3) how complex the program is to understand and use; (4) trialability, or the extent to which a potential user can test or experiment with a program before committing to adoption; and (5) observability (ie, the extent to which the program provides tangible outcomes). Most users learned about the Rx for Change website from another colleague, which suggests that colleagues perceived the website and its materials to possess a relative advantage over other available sources. This perception is consistent with findings from a prior study, in which the majority of faculty respondents $(89.9 \%)$ rated the website as either very or extremely useful [53]. Compatibility was shown by the fact that website registrants' most commonly cited intention for use of the curricular materials was to enhance their own knowledge and skills. Trialability and perceived acceptability of the complexity of the Rx for Change program were evident by the large number of registrations and continued use over time. An observable result was the large number of logins and file downloads from the website.

Previous findings suggest that the availability of a website to host shared teaching materials is a useful resource for health professional educators, and users report appreciation for access to regularly updated teaching content [33]. In our study, the most frequent referral source was a faculty member or a colleague $(33.4 \%)$. These findings are consistent with those identified in the evaluation of a web-based mental health portal, for which the highest utilization was among individuals personally invited to visit the website [54]. Thus, an effective mode of dissemination is learning about the program or its website from a professional or social network. Although no proactive efforts were made to alert users about updates or new content, this is a strategy that could be considered in the future as well as a brief survey of user needs to provide guidance for future program enhancements. Another area of future research 
is assessing important aspects of the website such as the website's readability, quality of information, credibility, and design.

\section{Limitations}

Limitations of this study include a possibility of duplicate users who utilized different email addresses when registering on the website. This was addressed through a manual review, as described in the Methods. Additionally, the number of file downloads found in this study is an underestimate, because videos can be streamed and viewed directly on the website, without downloading. Also, the number of file downloads likely underestimates actual utilization in the classroom or in clinical practice. For example, an instructor or clinician might download the content once and use it on a regular basis until the next update of the program materials, and these implementation activities are not captured by the Rx for Change website. This study does not provide evidence that a shared curriculum website would contribute to changes in the prevalence of tobacco use, although it is well-documented that clinicians have a proven, positive impact on their patients' ability to quit and therefore training is warranted [6]. Finally, because the ability to evaluate the long-term utilization of the shared curricular resources is fully dependent on the ability to maintain the quality and accessibility of the materials, the sustainability of any program is significantly challenged without ongoing funding and personal commitment of the program creators.

\section{Conclusions}

The $\mathrm{Rx}$ for Change website utilization data demonstrated sustained use, providing immediate access to shared, evidence-based tobacco cessation teaching and practice tools for educators and clinicians since 2004. The website had a broad interprofessional reach, which increases the likelihood of tobacco users receiving assistance from multiple types of health care providers. The consistent utilization over time and large number of downloads provided evidence for the feasibility and utility of a public access website hosting a shared tobacco cessation curriculum for health professionals. The shared curriculum concept, in tandem with a frequently updated website to host curricular materials, can be replicated for other topics of public health importance.

\section{Acknowledgments}

Scott Northwood created and has maintained the website since 2004. Drs Noll Campbell and Alan Zillich provided critical feedback on the manuscript. Jodi Prochaska, Frank Vitale, and members of the University of California San Francisco Smoking Cessation Leadership Center have created content for the Rx for Change website and have promoted the program's use for training health professionals for nearly 2 decades.

The Rx for Change program has been funded by the National Cancer Center, grants R25 CA 90720, R25 CA 174665, and R25 CA 236637 to KSH.

\section{Conflicts of Interest}

RLC and KSH created and maintain the Rx for Change program and the curriculum website.

\section{References}

1. Tobacco Fact Sheets. World Health Organization. 2019. URL: https://www.who.int/news-room/fact-sheets/detail/tobacco [accessed 2021-04-27]

2. National Center for Chronic Disease Prevention and Health Promotion (US) Office on Smoking and Health. The Health Consequences of Smoking - 50 Years of Progress: A Report of the Surgeon General. Atlanta, GA: Centers for Disease Control and Prevention; 2014.

3. Cornelius ME, Wang TW, Jamal A, Loretan CG, Neff LJ. Tobacco Product Use Among Adults - United States, 2019. MMWR Morb Mortal Wkly Rep 2020 Nov 20;69(46):1736-1742 [FREE Full text] [doi: 10.15585/mmwr.mm6946a4] [Medline: $\underline{33211681]}$

4. Hatsukami DK, Carroll DM. Tobacco harm reduction: Past history, current controversies and a proposed approach for the future. Prev Med 2020 Nov;140:106099. [doi: 10.1016/j.ypmed.2020.106099] [Medline: 32335031]

5. Campaign for Tobacco-Free Kids. URL: http://tobaccofreekids.org/research/factsheets/pdf/0097.pdf [accessed 2021-04-27]

6. Fiore M, Jaén C, Baker T. Treating Tobacco Use and Dependence: 2008 Update: Clinical Practice Guideline. Agency for Healthcare Research and Quality. 2008. URL: https://www.ahrq.gov/prevention/guidelines/tobacco/clinicians/update/index. html [accessed 2021-04-27]

7. Smoking Cessation: A Report of the Surgeon General. U.S. Department of Health and Human Services, Centers for Disease Control and Prevention, National Center for Chronic Disease Prevention and Health Promotion, Office on Smoking and Health. URL: https://www.hhs.gov/sites/default/files/2020-cessation-sgr-full-report.pdf [accessed 2021-04-27]

8. Marcy TW, Skelly J, Shiffman RN, Flynn BS. Facilitating adherence to the tobacco use treatment guideline with computer-mediated decision support systems: physician and clinic office manager perspectives. Prev Med 2005 Aug;41(2):479-487. [doi: 10.1016/j.ypmed.2004.11.026] [Medline: 15917044]

9. Satterfield JM, Gregorich SE, Kalkhoran S, Lum PJ, Bloome J, Alvarado N, et al. Computer-Facilitated 5 A's for Smoking Cessation: A Randomized Trial of Technology to Promote Provider Adherence. Am J Prev Med 2018 Jul;55(1):35-43 [FREE Full text] [doi: 10.1016/j.amepre.2018.04.009] [Medline: 29929682] 
10. Rx for Change: Clinician-Assisted Tobacco Cessation program, 1999-2021. URL: https://rxforchange.ucsf.edu [accessed 2021-04-27]

11. Ferry LH, Grissino LM, Runfola PS. Tobacco dependence curricula in US undergraduate medical education. JAMA 1999 Sep 01;282(9):825-829. [doi: 10.1001/jama.282.9.825] [Medline: 10478687]

12. Spangler JG, George G, Foley KL, Crandall SJ. Tobacco intervention training: current efforts and gaps in US medical schools. JAMA 2002 Sep 04;288(9):1102-1109. [doi: 10.1001/jama.288.9.1102] [Medline: 12204079]

13. Montalto NJ, Ferry LH, Stanhiser T. Tobacco dependence curricula in undergraduate osteopathic medical education. J Am Osteopath Assoc 2004 Aug;104(8):317-323. [Medline: 15345701]

14. Loranger M, Simms K, Pipe A. Smoking cessation counselling training in the pre-clerkship curriculum of Canadian medical schools: A national survey. Can Med Educ J 2018 May;9(2):e5-e10 [FREE Full text] [Medline: 30018679]

15. Richmond R, Zwar N, Taylor R, Hunnisett J, Hyslop F. Teaching about tobacco in medical schools: a worldwide study. Drug Alcohol Rev 2009 Sep;28(5):484-497. [doi: 10.1111/j.1465-3362.2009.00105.x] [Medline: 19737207]

16. Heath J, Andrews J, Thomas SA, Kelley FJ, Friedman E. Tobacco dependence curricula in acute care nurse practitioner education. Am J Crit Care 2002 Jan;11(1):27-33. [Medline: 11785554]

17. Wewers ME, Kidd K, Armbruster D, Sarna L. Tobacco dependence curricula in U.S. baccalaureate and graduate nursing education. Nurs Outlook 2004;52(2):95-101. [doi: 10.1016/j.outlook.2003.09.007] [Medline: 15073590]

18. Sarna L, Danao LL, Chan SSC, Shin SR, Baldago LA, Endo E, et al. Tobacco control curricula content in baccalaureate nursing programs in four Asian nations. Nurs Outlook 2006;54(6):334-344. [doi: 10.1016/j.outlook.2006.09.005] [Medline: 17142152]

19. Chan SS, Sarna L, Danao LL. Are nurses prepared to curb the tobacco epidemic in China? A questionnaire survey of schools of nursing. Int J Nurs Stud 2008 May;45(5):706-713. [doi: 10.1016/j.ijnurstu.2006.12.008] [Medline: 17336307]

20. Hudmon KS, Bardel K, Kroon LA, Fenlon CM, Corelli RL. Tobacco education in U.S. schools of pharmacy. Nicotine Tob Res 2005 Apr;7(2):225-232. [doi: 10.1080/14622200500055392] [Medline: 16036279]

21. El Hajj MS, Awaisu A, Saleh RA, Al Hamad NM, Kheir N, Zeenny RM, et al. Tobacco-related education in schools of pharmacy in the Middle East: a multinational cross-sectional study. Nicotine Tob Res 2018 Apr 02;20(5):561-567. [doi: 10.1093/ntr/ntx031] [Medline: 28164230]

22. Davis JM, Koerber A. Assessment of tobacco dependence curricula in U.S. dental hygiene programs. J Dent Educ 2010 Oct;74(10):1066-1073. [Medline: 20930237]

23. Pignataro RM, Gurka MJ, Jones DL, Kershner RE, Ohtake PJ, Stauber WT, et al. Tobacco cessation counseling training in US entry-level physical therapist education curricula: prevalence, content, and associated factors. Phys Ther 2014 Sep;94(9):1294-1305 [FREE Full text] [doi: 10.2522/ptj.20130245] [Medline: 24830717]

24. Houston LN, Warner M, Corelli RL, Fenlon CM, Hudmon KS. Tobacco education in US physician assistant programs. J Cancer Educ 2009;24(2):107-113. [doi: 10.1080/08858190902854475] [Medline: 19431026]

25. Jordan TR, Khubchandani J, Wiblishauser M, Glassman T, Thompson A. Do respiratory therapists receive training and education in smoking cessation? A national study of post-secondary training programs. Patient Educ Couns 2011 Oct;85(1):99-105. [doi: 10.1016/j.pec.2010.10.022] [Medline: 21106321]

26. Hudmon KS, Mark M, Livin AL, Corelli RL, Schroeder SA. Tobacco education in U.S. respiratory care programs. Nicotine Tob Res 2014 Oct;16(10):1394-1398 [FREE Full text] [doi: 10.1093/ntr/ntu113] [Medline: 25031314]

27. Hudmon KS, Corelli RL, Chung E, Gundersen B, Kroon LA, Sakamoto LM, et al. Development and implementation of a tobacco cessation training program for students in the health professions. J Cancer Educ 2003;18(3):142-149. [doi: 10.1207/S15430154JCE1803 07] [Medline: 14512261]

28. Kelly A. The Curriculum: Theory and Practice, 6th edition. Thousand Oaks, CA: SAGE Publications, Inc; 2009.

29. Rogers E. Diffusion of Innovations, 5th edition. New York, NY: Free Press; 2003.

30. Steinert Y, Mann K, Anderson B, Barnett BM, Centeno A, Naismith L, et al. A systematic review of faculty development initiatives designed to enhance teaching effectiveness: A 10-year update: BEME Guide No. 40. Med Teach 2016 Aug;38(8):769-786. [doi: 10.1080/0142159X.2016.1181851] [Medline: 27420193]

31. VirtualRx: Rx for Change virtual patients, 2016-2021. URL: https://virtualrx.ucsf.edu [accessed 2021-04-27]

32. IBM SPSS Statistics for Windows, Version 26.0. IBM Corporation. Armonk, NY: IBM Corp; 2019. URL: https://www. ibm.com/analytics/spss-statistics-software [accessed 2021-04-27]

33. Elkhadragy N, Corelli RL, Russ AL, Snyder ME, Clabaugh M, Hudmon KS. Faculty perceptions of a tobacco cessation train-the-trainer workshop and experiences with implementation: A qualitative follow-up study. Res Social Adm Pharm 2019 Dec;15(12):1436-1445 [FREE Full text] [doi: 10.1016/j.sapharm.2019.01.005] [Medline: 30737194]

34. Taylor GMJ, Dalili MN, Semwal M, Civljak M, Sheikh A, Car J. Internet-based interventions for smoking cessation. Cochrane Database Syst Rev 2017 Sep 04;9:CD007078 [FREE Full text] [doi: 10.1002/14651858.CD007078.pub5] [Medline: 28869775]

35. Pharmacogenomics Education Program (PharmGenEdTM). University of California San Diego. URL: http:/ /pharmacogenomics.ucsd.edu [accessed 2021-04-27]

36. Infectious Diseases Educator Network (ID-EN). University of California, San Francisco. URL: https://iden.ucsf.edu/ [accessed 2021-04-27] 
37. Hall DL, Drab SR, Campbell RK, Meyer SM, Smith RB. A Web-based interprofessional diabetes education course. Am J Pharm Educ 2007 Oct 15;71(5):93 [FREE Full text] [doi: 10.5688/aj710593] [Medline: 17998990 ]

38. Kelley FJ, Heath J, Crowell N. Using the Rx for Change tobacco curriculum in advanced practice nursing education. Crit Care Nurs Clin North Am 2006 Mar;18(1):131-8, xiv. [doi: 10.1016/j.ccell.2005.11.003] [Medline: 16546016]

39. Khan N, Anderson JR, Du J, Tinker D, Bachyrycz AM, Namdar R. Smoking cessation and its predictors: results from a community-based pharmacy tobacco cessation program in New Mexico. Ann Pharmacother 2012 Sep;46(9):1198-1204. [doi: 10.1345/aph.1P146] [Medline: 22911338]

40. Chen TC, Hamlett-Berry KW, Watanabe JH, Bounthavong M, Zillich AJ, Christofferson DE, et al. Evaluation of multidisciplinary tobacco cessation training program in a large health care system. American Journal of Health Education 2015 May 08;46(3):165-173. [doi: 10.1080/19325037.2015.1023475]

41. Kristina SA, Thavorncharoensap M, Pongcharoensuk P, Prabandari YS. Impact of smoking cessation training for community pharmacists in Indonesia. Asian Pac J Cancer Prev 2015;16(8):3319-3323 [FREE Full text] [doi: 10.7314/apjcp.2015.16.8.3319] [Medline: 25921138]

42. Surachman F, Anggadiredja K, Rahmawati SF, Zazuli Z. Smoking cessation counseling program: a pilot study on college smokers. KLS 2019 Feb 28;4(10):411-419. [doi: 10.18502/kls.v4i10.3746]

43. Prochaska JJ, Benowitz NL, Glantz SA, Hudmon KS, Grossman W. Cardiology Rx for Change: improving clinical attention to tobacco use and secondhand smoke exposure in cardiology. Clin Cardiol 2011 Dec;34(12):738-743 [FREE Full text] [doi: 10.1002/clc.20982] [Medline: 21987417]

44. Waheedi M, Al-Tmimy AM, Enlund H. Preparedness for the smoking cessation role among health sciences students in Kuwait. Med Princ Pract 2011;20(3):237-243 [FREE Full text] [doi: 10.1159/000321273] [Medline: 21454993]

45. Williams DM. Preparing pharmacy students and pharmacists to provide tobacco cessation counselling. Drug Alcohol Rev 2009 Sep;28(5):533-540. [doi: 10.1111/j.1465-3362.2009.00109.x] [Medline: 19737211]

46. Schmelz AN, Nixon B, McDaniel A, Hudmon KS, Zillich AJ. Evaluation of an online tobacco cessation course for health professions students. Am J Pharm Educ 2010 Mar 10;74(2):36 [FREE Full text] [doi: 10.5688/aj740236] [Medline: 20414451]

47. Heath J, Kelley FJ, Andrews J, Crowell N, Corelli RL, Hudmon KS. Evaluation of a tobacco cessation curricular intervention among acute care nurse practitioner faculty members. Am J Crit Care 2007 May;16(3):284-289. [Medline: 17460322]

48. Butler KM, Rayens MK, Zhang M, Maggio LG, Riker C, Hahn EJ. Tobacco dependence treatment education for baccalaureate nursing students. J Nurs Educ 2009 May;48(5):249-254. [Medline: 19476029]

49. Hudmon KS, Vitale FM, Elkhadragy N, Corelli RL, Strickland SL, Varekojis SM, et al. Evaluation of an interprofessional tobacco cessation train-the-trainer program for respiratory therapy faculty. Respir Care 2021 Mar;66(3):475-481. [doi: 10.4187/respcare.07791] [Medline: 32900914]

50. Amole J, Heath J, Joshua TV, McLear B. Online tobacco cessation education to optimize standards of practice for psychiatric mental health nurses. Nurs Clin North Am 2012 Mar;47(1):71-79. [doi: 10.1016/j.cnur.2011.10.006] [Medline: 22289399]

51. Prochaska JJ, Fromont SC, Hudmon KS, Cataldo JK. Designing for dissemination: development of an evidence-based tobacco treatment curriculum for psychiatry training programs. J Am Psychiatr Nurses Assoc 2009 Feb;15(1):24-31 [FREE Full text] [doi: 10.1177/1078390308329536] [Medline: 19587844$]$

52. Glasgow RE, Vogt TM, Boles SM. Evaluating the public health impact of health promotion interventions: the RE-AIM framework. Am J Public Health 1999 Sep;89(9):1322-1327. [doi: 10.2105/ajph.89.9.1322] [Medline: 10474547]

53. Elkhadragy N, Corelli RL, Zillich AJ, Campbell NL, Hudmon KS. Long-term evaluation of a train-the-trainer workshop for pharmacy faculty using the RE-AIM framework. Res Social Adm Pharm 2020 Nov 30:1. [doi:

10.1016/j.sapharm.2020.11.018] [Medline: 33551208]

54. Song MJ, Ward J, Choi F, Nikoo M, Frank A, Shams F, et al. A Process Evaluation of a Web-Based Mental Health Portal (WalkAlong) Using Google Analytics. JMIR Ment Health 2018 Aug 20;5(3):e50 [FREE Full text] [doi: 10.2196/mental.8594] [Medline: 30126832]

\section{Abbreviations}

ANDS: alternative nicotine delivery systems

OSCE: objective structured clinical examination 
Edited by G Eysenbach; submitted 27.05.20; peer-reviewed by S Bidmon, A Abubakar; comments to author 07.09.20; revised version received 31.12.20; accepted 13.04.21; published 25.05 .21

Please cite as:

Elkhadragy N, Aviado J, Huang H, Corelli RL, Hudmon KS

Shared Tobacco Cessation Curriculum Website for Health Professionals: Longitudinal Analysis of User and Utilization Data Over a Period of 15 Years

JMIR Med Educ 2021;7(2):e20704

URL: https://mededu.jmir.org/2021/2/e20704

doi: $10.2196 / 20704$

PMID:

CNervana Elkhadragy, Jeremie Aviado, Henry Huang, Robin L Corelli, Karen Suchanek Hudmon. Originally published in JMIR Medical Education (https://mededu.jmir.org), 25.05.2021. This is an open-access article distributed under the terms of the Creative Commons Attribution License (https://creativecommons.org/licenses/by/4.0/), which permits unrestricted use, distribution, and reproduction in any medium, provided the original work, first published in JMIR Medical Education, is properly cited. The complete bibliographic information, a link to the original publication on https://mededu.jmir.org/, as well as this copyright and license information must be included. 